\title{
Optimal technical and economic strategy for retrofitting residential buildings in Romania
}

\author{
Mihail-Bogdan CĂRUȚAȘIU \\ University Politehnica of Bucharest, Bucharest, Romania \\ carutasiu@gmail.com \\ Constantin IONESCU \\ University Politehnica of Bucharest, Bucharest, Romania \\ Horia NECULA \\ University Politehnica of Bucharest, Bucharest, Romania
}

\begin{abstract}
The European Legislation is very strict regarding the importance of reducing the energy consumption in buildings sector. The importance of achieving nearly zero energy consumption levels for both new and existing buildings is also highlighted in each Members' national legislation. Moreover, the high percentage of existing buildings across European Union, indicates that they need to be adequately approached in order to achieve the ambitious energy efficiency goals. This implies creating the optimal technical and financial retrofit strategies regarding minimizing the energy consumption without lowering the interior comfort levels. In Romania, there is no unitary strategy aiming to maximize the energy efficiency in buildings which also takes into consideration the financial part of the process. Moreover, there are no known national guidelines and strategies for buildings retrofit which takes into consideration a wide range of equipment. The Romanian Energy Efficiency Strategy presents few possibilities resulted from integrating renewable energy sources within typical Romanian buildings, while the Buildings Performance Institute Europe conducted a research regarding the potential of nearly Zero Energy Buildings implementation across Romanian territory. Both studies refer only to typical buildings and do not present a large perspective for retrofitting action, while the financial study is not properly presented. Thus, this paper develops a comprehensive financial study which could be used as guideline by stakeholders, in order to find the best technical solution for decreasing the final energy consumption in Romanian residential buildings. Using the RETScreen software and its economical features, there were developed several energy efficiency solutions, and by analyzing the financial benefits implied, the best solution was chosen. By adopting the solutions presented within this feasibility study, the energy consumption of buildings should be significantly reduced.
\end{abstract}

Keywords: zero energy buildings, retrofitting, feasibility study, energy efficiency, RETScreen.

\section{Introduction}

The European Union (EU) energetic strategy aims drastic reduction of greenhouse gas emission across its territory, by reducing the energy consumption in key sectors. The latest surveys estimated that the buildings sector is responsible for a major share of emissions (35\%), due to the fact that is the largest end-use energy consumer in Europe, with a total share of $40 \%$ (B. Anastasiu et al, 2011). Moreover, the fact that this sector is continuously growing, determined the European Parliament to introduce "the nearly Zero Energy Buildings" (nZEB) principle as cornerstone for new and retrofit buildings starting from 2018 onwards (Directive 2010/31/EU). In the EU, there are approximately 75\% residential buildings, from which, only about 17\% were built between 1991 and 2010, thus a 
substantial share of this sector is older than 50 years (more than $40 \%$ were built before 1960s) (BPIE, 2011). Due to these facts, the EU's Energy Plan from 2011 stated that "the sectors that deserves the highest attention are residential, tertiary and transport", among which, the residential sector has the highest technical potential for increasing the energy efficiency, estimated at 30\% (BPIE, 2011).

In Romania, according to the census from 2011, there are slightly over 5.1 million buildings, totaling approximately 0.5 billion $\mathrm{m}^{2}$ of useful area, from which, more than $85 \%$ is represented by dwellings (BPIE, 2012). The Romanian buildings are responsible for more than $44 \%$ of final energy consumption, while more than a half of the existing buildings were built before 1970, and more than $90 \%$ before 1989, thus the energy performances are low. A typical building in Romania has an energy performance level ranging from 150 to 400 $\mathrm{kWh} / \mathrm{m}^{2} /$ year, from which, more than $55 \%$ is required for heating the interior space (EEA, 2011). According to the latest Romanian Energetic Strategy, these statistics implies great efficiency potential for this sector, estimated at 35-50\% for dwellings and $13-19 \%$ for tertiary buildings. To achieve these daring energy efficiency goals, it is necessary apply different methods for decreasing the energy intensity for both old and new buildings. While for new buildings there are a number of standards to be applied in order to achieve an increased efficiency (e.g. passive-house standard), the most difficult part is to find the optimal strategy to retrofit the existing buildings. This is a very difficult task for Governments, due to the complexity of the given problem: specific climate, efficiency potential, numerical evaluation criteria, available technology and budget, and last but not least, cultural, psychological and aesthetics aspects. Moreover, the importance of renovating the buildings constructed prior to any energy performance requirements, is highlighted in the Energy Efficiency Directive (Directive 2012/27/EU), which required Member States to establish long-term strategies for mobilizing investment in the renovation on national buildings stocks.

Even if the need of creating healthy and comfortable environment in dwellings started since ancient times, the concerns regarding the efficiency of buildings gained popularity due to the recent oil crisis and global warming menace (Ionescu et al., 2015). For Bucharest climate conditions, there have been conducted studies regarding the potential of increasing the energy efficiency of new buildings, by analyzing the behavior of the passive house concept (Carutasiu et al., 2015; Danu et al., 2015). The results showed that the energy consumption can be decreased by combining renewable energy sources with an efficient HVAC (Heating Ventilating and Air Conditioning) system, a special type of architecture, compact shape and very good insulation with minimum thermal bridges. Although the presented approach provided very good results, it does not refer to existing buildings, as it is a construction standard. Thus, this paper presents few possibilities of decreasing the energy consumption in residential buildings, by conducting a cost and technological study in order to choose the best solution.

\section{Literature review}

\section{Retrofit strategies and approaches}

In recent years, there have been developed national and local strategies focusing on increasing the energy efficiency of existing buildings, subjected to retrofit actions. For example, in a study conducted by the Building Performance Institute Europe (BIPE, 2012) 
regarding the implementation on nZEB (nearly Zero Energy Buildings) in Romania, the authors defined three reference buildings: detached single-family houses, multi-family houses and office buildings and used a dynamical software (TRNSYS) to simulate the energy requirement based on some assumed thermal proprieties of walls and HVAC (Heating, Ventilating and Air Conditioning) systems. Subsequently, they modify these parameters and added renewable energy systems, resulting 5 variants for nZEB for each reference building. The study was concluded with a financial analysis of the previously obtained solutions, but their approach cannot be widely used to the complexity of the simulation software and the assumptions made. The same approach can be found in the following national studies: (BIPE, 2014), and the same issues were found: the degree of difficulty of the proposed simulation method and the lack of usability among non-experts. These approaches were proved to be difficult to use and are time consuming to develop the accurate mathematical model. Moreover, the complexity of the used methods make difficult to easily integrate the financial feature. Thus, it emerged the necessity of using simpler and focused analysis tools. For this paper, the RETScreen analysis tool was used in order to develop the best retrofit scenario for a residential multi-unit building in Romanian climate conditions.

\section{RETScreen analysis tool}

In the last few years, RETScreen software gained popularity among energy efficiency experts and, with more than 200,000 downloads by 2010 become the most used simulation and analysis tool (D. Connolly et al., 2010). This Clean Energy Management Software was developed by Natural Resources Canada, in conjunction with the Canadian Government and different partners from industrial and academic fields and is a powerful tool to analyze the feasibility of renewable energy projects, helping the decision-makers to find the optimal cost-effective solution (Leng et al., 2004). Using RETScreen software, the user can analyze comprehensive projects regarding the implementation of many clean energy technologies, such as: renewable energy electricity generating technologies (wind, hydro and photovoltaic energy systems), renewable energy heating and cooling technologies (biomass, solar-air, solar-water, passive solar heating systems and ground-source heat pumps), combined heat and power (CHP) technologies, biofuels, ventilation heat recovery and efficient refrigeration systems, efficient lighting systems, tidal and wave power, buildings' efficiency measures, etc. (RETScreen Engineering \& Cases Toolbox, 2005). Compared with other tools, it presents the advantage that is relatively easy to use (compared with TRNSYS or EnergyPlus), is free and can accurately evaluate both electrical and thermal systems (as compared with HOMER, energyPRO, etc.) (Lee et al., 2012). Moreover, the software has integrated features, including comprehensive databases containing climate data and technologies, as well as suggestive case studies and templates.

In recent years, due to the fact that the developers continuously extended its usability and flexibility, RETScreen gained popularity also among scientific researchers. Moreover, the current concerns about increasing buildings' energy efficiency are quantified in a series of papers which assesses the impact of different strategies over the mitigation of energy consumption in buildings. Lee et al. conducted a study to preliminary determine the optimal size for renewable energy systems to be implemented into buildings (Lee et al., 2012). Salata et al., 2012 determined the best configuration of renewable energy sources which could be used to satisfy the energy demands of some historic buildings in Rome, Italy. 
Kim et al., 2016 and Koo et al., 2016 used RETScreen in conjunction with multi-objective optimization models in order to find the optimal solutions for integrating solar electric and thermal renewable energy systems into rooftops of the buildings. The literature survey indicated that the RETScreen software provides satisfactory results for feasibility studies, making it suitable for the subject of this paper.

\section{Simulations and results}

\section{Simulations}

RETScreen package allows users to develop different energy efficiency models by implementing a five-step procedure, including: energy, cost, emission, financial and sensitivity/risk analysis. Using these features, the authors analyzed the possibility to achieve the desired energy efficiency in residential buildings. The energy consumption of a building is influenced by the exterior environmental conditions of the location, constructions materials, integrated systems, occupancy, etc. Thus, the first step in conducting an efficiency analysis is to select the climate features of the building's location. This enables the database containing weather files, and the data for Bucharest can be analyzed in Figure 1.

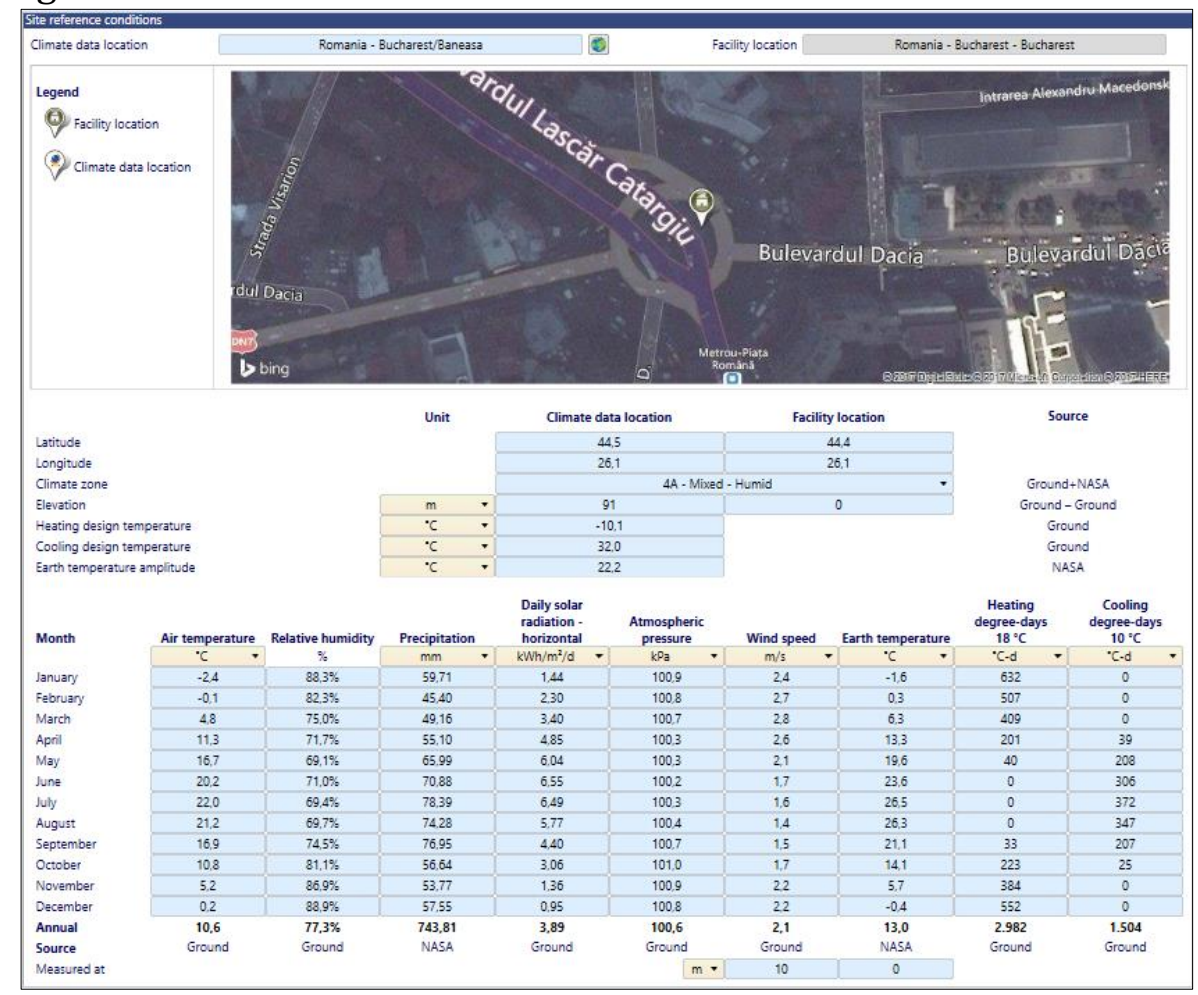

Figure 1. Climatic data for Bucharest (Băneasa), Romania

Source: RETScreen software database interface.

As highlighted in Figure 1, the weather data provided for computing the energy consumption is composed of monthly average values of air temperature, relative humidity, precipitation, horizontal daily solar radiation, wind speed (measured at $10 \mathrm{~m}$ altitude), ground temperature (measured at $0 \mathrm{~m}$ depth), and, most important, heating and cooling degree days. Moreover, the RETScreen database offers the same type of data for 57 towns in 
Romania, including Întorsura Buzăului and Omu Mountain, zones characterized by very low temperatures during winter. This feature allows the users to analyze the costs implied for energy efficiency for a wide climatic area, increasing its applicability. For Bucharest, RETScreen database offers climatic data collected from both Băneasa and Otopeni weather stations. Regardless of the chosen climate zone, the fundament of RETScreen is to compare the benchmark case with the results of the implemented energy efficiency strategies, resulting a comprehensive economic and technical analysis. For this paper, the authors analyzed the possibility to reduce the energy consumption for a typical residential building, placed in Piața Romană, Bucharest, Romania, as highlighted in Figure 1. Therefore, the apartment building, or multi-unit housing, was simulated using the RETScreen software, in order to estimate the best cost-effective energy efficiency strategy.

The climate data and the facility information were chosen and integrated within the Virtual Energy Analyzer, a feature which allows the user to estimate the energy savings, employing a comprehensive benchmark system for comparison. The facility was considered representative for Romanian buildings culture and has a total useful surface of $1300 \mathrm{~m}^{2}$ (small flats building). Moreover, the base case energy consumption, for this representative type of building, the predicted total energy consumption was $311 \mathrm{kWh} / \mathrm{m}^{2} /$ year, totaling $404.881 \mathrm{kWh} /$ year. The most feasible energy reduction target was considered to be $30 \%$, as highlighted in Figure 2, thus $121.464 \mathrm{kWh} /$ year final energy savings.

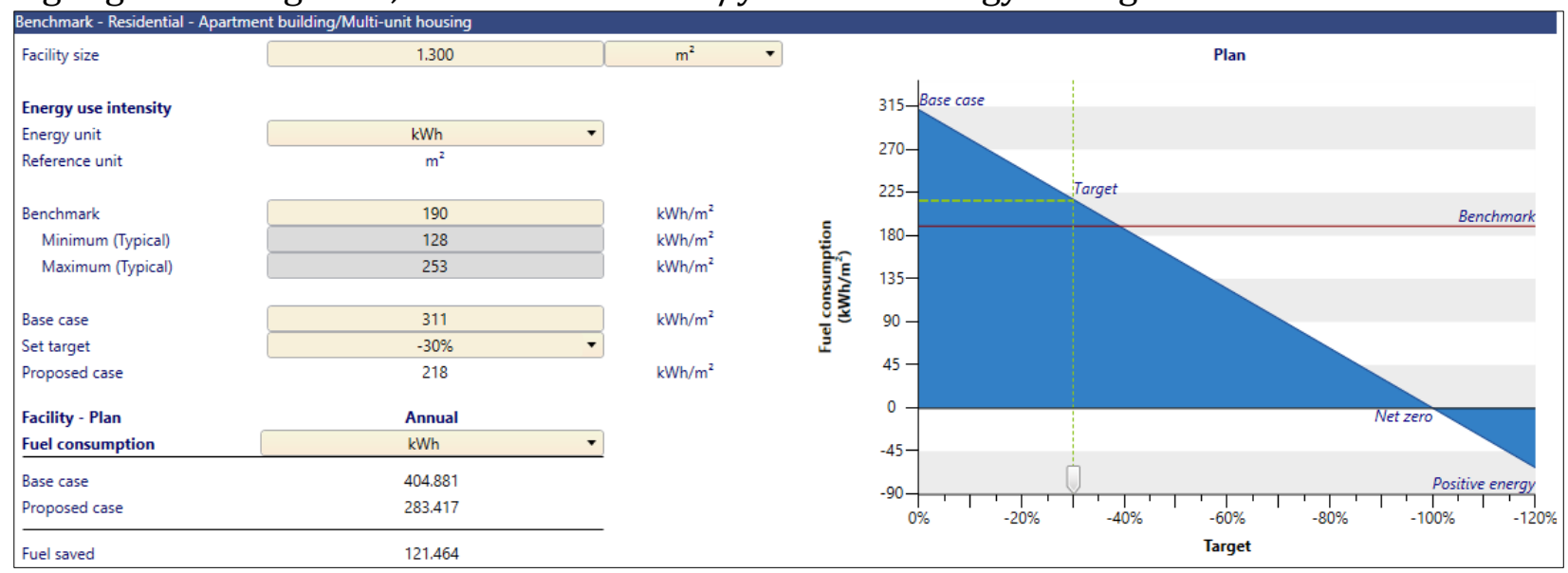

Figure 2. Energy consumption and reduction target for the analyzed facility

Source: RETScreen software simulation results.

The proposed measures for achieving these reductions are: reducing the fresh air flow through the ventilation system and install demand-control ventilation system based on $\mathrm{CO}$ emissions for the parking spots, changing the illumination infrastructure with a more efficient one, reducing the hot water usage and install renewable energy sources onsite (solar water heater and photovoltaic systems). Even if the energy intensity remains above the nearly zero energy buildings' standard, this percentage of reduction represents the optimal solution from financial point of view. The software allows the users to create different scenarios and to analyze the financial impact of divers strategies and within this paper only the best cost-effective solution was presented. 


\section{Results and discussions}

After the energy audit and energy reduction simulation, it was conducted the environment and financial analyzes. For this, each efficiency measure is quantified by both its cost and energy reduction potential. For a better understanding, the cost-effectiveness of changing the illumination system and integrating roof-mounting photovoltaic (PV) panels are discussed.

For the lights infrastructure in individuals' apartments, the proposed efficiency method is to change all laps, without lowering the illumination level, which, as suggested in norms, should not be under 100 lux for residential usage. The base case infrastructure consists of using usual compact fluorescent screw-in laps, with low efficiency (56.7 lm/W). Changing these laps with LEDs (Light Emitting Diode) with an efficiency of $94 \mathrm{~lm} / \mathrm{W}$ and a lifetime of 50000 hours, the energy reduction was estimated at $2803 \mathrm{kWh} / \mathrm{year}$, or $21.7 \%$. Moreover, the costs of the equipment indicate a simple payback time of 18.2 year. The same type of analysis was conducted for the illuminated areas: corridor, parking garage, exterior façade and exterior doors. Moreover, the infrastructure proposed for each case can be analyzed in Table 1, in which, BC is the base case and PC is the proposed case.

Table 1. Comparison between illumination systems used for efficiency

\begin{tabular}{|c|c|c|c|c|c|c|c|c|}
\hline Zone & \multicolumn{2}{|c|}{ Corridor } & \multicolumn{2}{c|}{ Garage } & \multicolumn{2}{c|}{ Exterior façade } & \multicolumn{2}{c|}{ Exterior doors } \\
\hline- & BC & PC & BC & PC & BC & PC & BC & PC \\
\hline Lamp type & $\begin{array}{c}\text { Fluorescent } \\
\text { T5 }\end{array}$ & LED & $\begin{array}{c}\text { Fluorescent } \\
\text { T8 }\end{array}$ & LED & $\begin{array}{c}\text { High pressure } \\
\text { sodium }\end{array}$ & LED & $\begin{array}{c}\text { High pressure } \\
\text { sodium }\end{array}$ & LED \\
\hline $\begin{array}{c}\text { Efficiency } \\
{[\text { lm/W] }}\end{array}$ & 90,6 & 100 & 85,5 & 100 & 104,6 & 67 & 104,6 & 67 \\
\hline No. lamps & 4 & 4 & 90 & 90 & 12 & 12 & 6 & 6 \\
\hline $\begin{array}{c}\text { Operating } \\
{[\mathrm{h} / \mathrm{w}]}\end{array}$ & 168 & 168 & 168 & 42 & 84 & 84 & 84 & 84 \\
\hline $\begin{array}{c}\text { Electricity } \\
{[\mathrm{kWh}]}\end{array}$ & 4345 & 2102 & 26017 & 3548 & 2943 & 1156 & 1472 & 578 \\
\hline $\begin{array}{c}\text { Costs } \\
{[€ / \text { piece] }}\end{array}$ & 38 & 58 & 32 & 58 & 20 & 50 & 20 & 50 \\
\hline $\begin{array}{c}\text { Payback } \\
{[\text { years] }}\end{array}$ & \multicolumn{2}{|c|}{2.8} & 1.3 & 52.4 & & & 52.4 \\
\hline
\end{tabular}

Source: Authors' own research.

Moreover, the same type of analysis is proposed for reducing even more the electricity consumption of the analyzed building. For this, the authors propose roofmounted photovoltaic panels, designed taking into consideration both efficiency and economic features. The PV panels are fixed (no solar tracking infrastructure - for financial reasons), mounted with a $44^{\circ}$ slope and $0^{\circ}$ azimuth angle. The 135 mono-Si panels have a nominal power of $27 \mathrm{~kW}$, thus, influenced by the Bucharest solar radiation (presented in Figure 1), implies $33 \mathrm{MWh}$ /year energy savings (considering the manufactures efficiency of $15,75 \%$ ). Moreover, the total area of the solar collectors is $171 \mathrm{~m}^{2}$, and are mounted on the building's roof. The losses due to the exterior temperature are considered to be maximum $15 \%$. The chosen inverter has a capacity of $24 \mathrm{~kW}$, an efficiency of $95 \%$ and miscellaneous losses estimated at $1 \%$. The manufacturer indicated a specific cost of $3300 € / \mathrm{kW}$, resulting a total investment of $89100 €$, while the OM savings are estimated at approximately $44 € / \mathrm{kW} /$ year (1188 € total). The simple payback of this solution is estimated at 42.3 years, 
indicating a longer period than the PV system's lifetime. In addition, the analyze performed over the proposed integrated renewable energy solar water system is detailed in Figure 3.

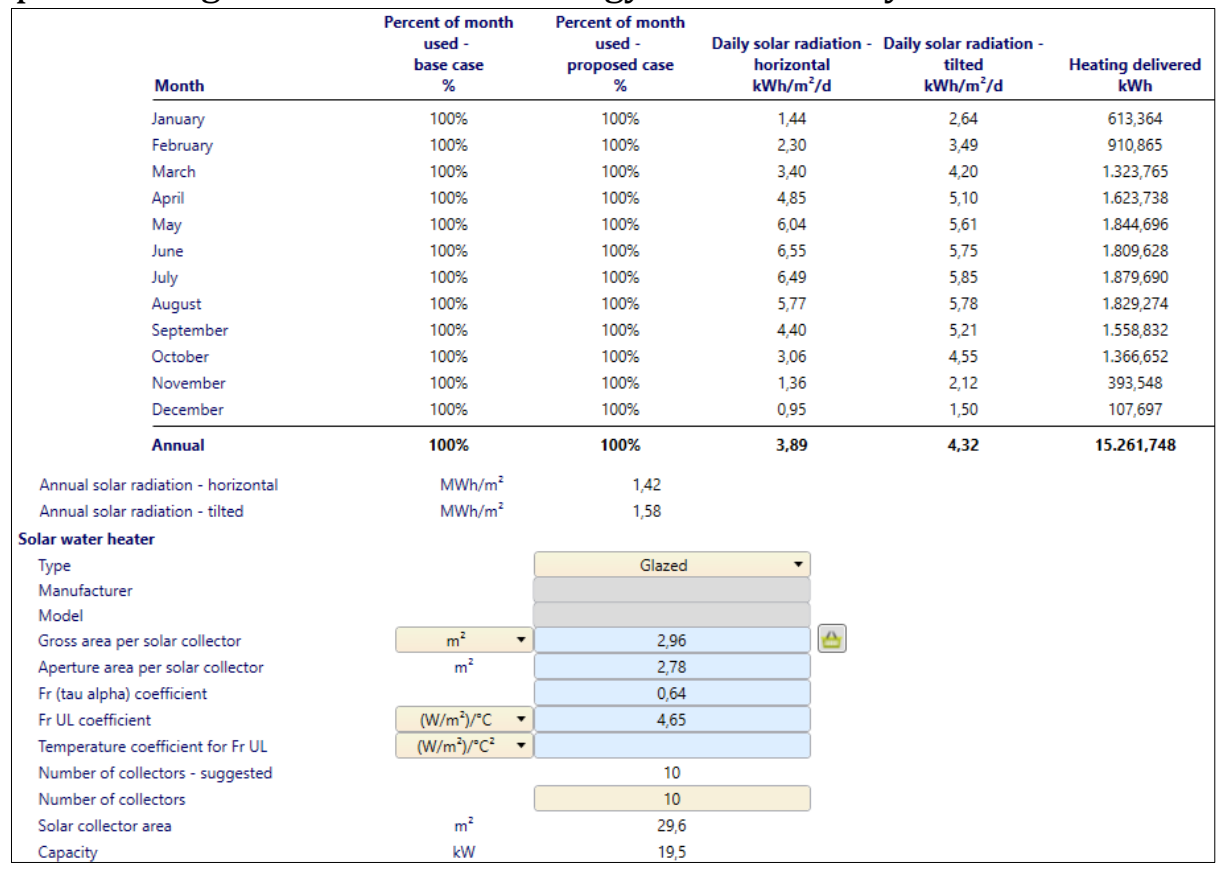

PICBE | 152

Figure 3. Technical data and hot water production of the solar system

Source: Authors' simulation in RETScreen.

Using this type of solar water heater combined with a $75 \mathrm{l} / \mathrm{m}^{2}$ storage system and an efficient heat exchanger, the solar fraction (representing the percentage of hot water provided by the system from total required hot water) was estimated at $42 \%$, while the initial cost increased at approximately $25000 €$, implying a playback period of 45.5 years.

Regarding the greenhouse gases emissions (GHG), the totality of the adopted energy reduction strategies has a significant impact. Considering the GHG emission factor of 0,536 $\mathrm{kgCO}_{2} / \mathrm{kWh}$ (representative for Romania), the gross annual emission reduction is estimated at approximately $100 \mathrm{tCO}_{2}$. Moreover, this quantity is equivalent with: approx. 18 cars and trucks not used, 42.385 litres of gasoline not consumed, 230 barrels of crude oil not consumes, 9 hectares of forest absorbing carbon or 34 tonnes of recycled waste. The total $\mathrm{GHG}$ reduction avenue is estimated at $99 \mathrm{tCO}_{2} /$ year $\left(1973 \mathrm{tCO}_{2}\right.$ over the project's lifetime).

After the energy and environmental impact, the authors simulated the project's financial impact. For this, the above presented assumptions were considered over the most important financial parameters: fuel cost escalation rate $-2 \%$, inflation rate: $2 \%$, discount rate $-9 \%$ and the project's life time -20 years.

Moreover, we did not take into consideration any incentives or grants provided by Government, for example. Form the total proposed investment, summing $194.762 €$, we considered a debt ratio of $70 \%$, representing $136.333 €$. Thus, the equity, representing the portion of the total investment required to finance the project is considered to be funded directly by the apartments' owners. The debt interest rate was set at 7\%, while the debt term is considered to last 15 years, resulting a yearly debt payment of approx. $15.000 €$ or $1250 € /$ month. The monthly payment for each apartment will not exceed $39 €$, representing approx. $12 \%$ of the Romanian minimum wage. Moreover, the software 
simulated the savings and revenue of the project, totaling $47.451 €$. The financial viability is detailed in Table 3, while the yearly cash flows (pre-tax and cumulative cash flows) are presented in Figure 4.

Table 3. Project's financial viability indexes

\begin{tabular}{|l|c|}
\hline Pre-tax IRR - equity [\%] & 16,2 \\
\hline Pre-tax IRR - assets [\%] & 3,4 \\
\hline Simple payback [years] & 9,2 \\
\hline Equity payback [years] & 7,3 \\
\hline Net Present Value [€] & 47.821 \\
\hline Annual life cycle saving [€/year] & 5.239 \\
\hline Benefit - Cost (B-C) ratio [-] & 1,8 \\
\hline Debt service coverage & 1,4 \\
\hline
\end{tabular}

PICBE | 153

Source: Authors' own research.

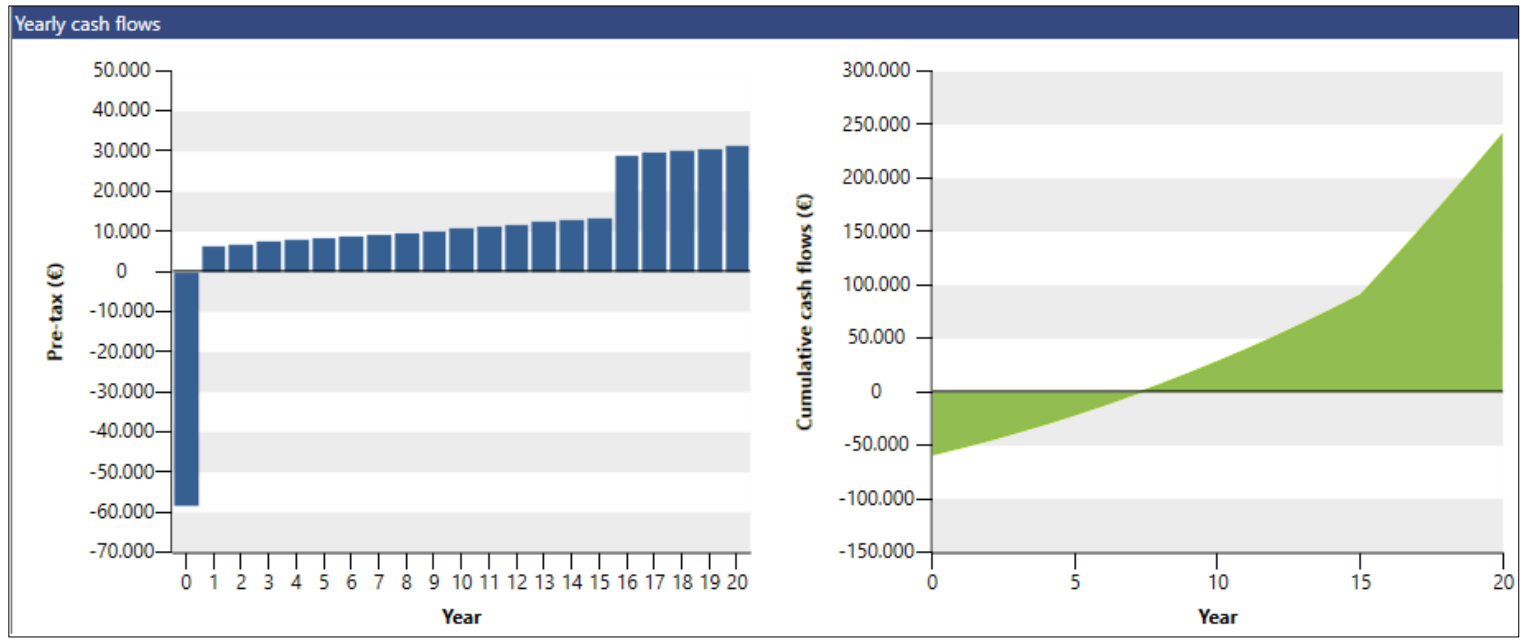

Figure 4. Project's yearly pre-tax and cumulative cash flows

Source: Authors' simulation in RETScreen.

This comprehensive financial analysis shows the project's feasibility, and, the resulted payback of 9,2 years (compared with the project's lifetime) strengthens the applicability of the proposed energy efficiency methods. Moreover, due to the renewable energy sources, the cumulative cash flow shows, that, starting from the eighth year of usage, the values are positive, increasing the project's feasibility. Without this measure, the project's payback period decreases at 4,4 years (compared with 9,2 years), but the overall benefits are also lowered. Moreover, the simple risk analysis performed over on the equity payback (detailed in Figure 5) strengthens the positive impact of the proposed energy efficiency solutions. 


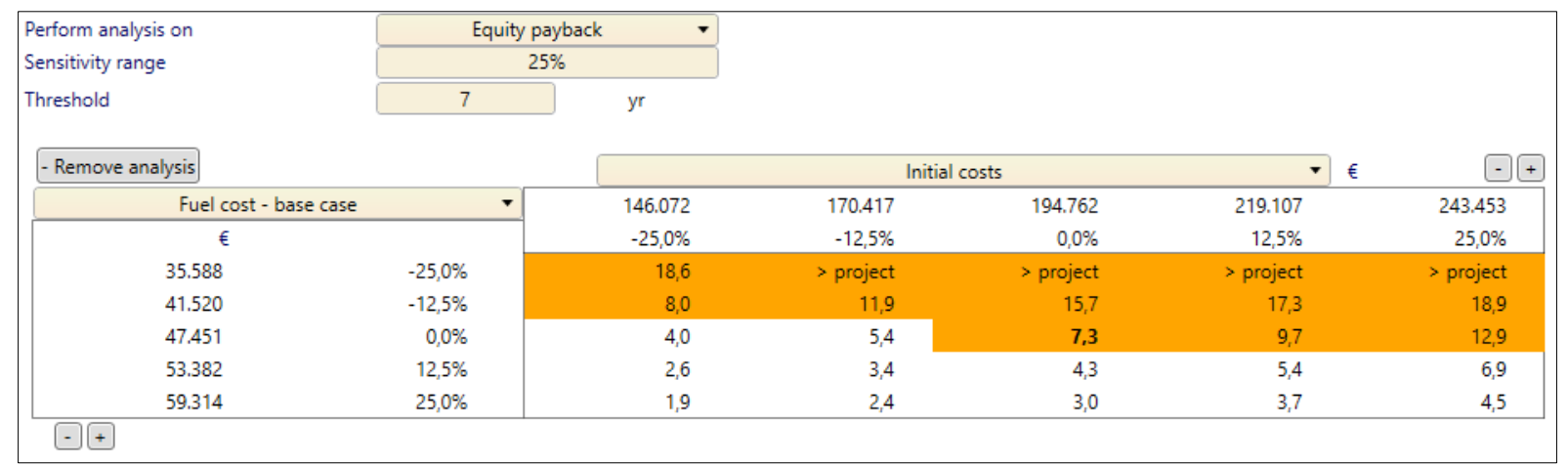

Figure 5. Project's sensitivity analysis performed on the equity payback

PICBE | 154

Source: Authors' simulation in RETScreen.

\section{Conclusion}

This paper analyses the technical and financial possibility to increase the energy efficiency of a residential multi-unit housing located in Bucharest, Romania. The idea emerged from the need of the European Union's Members to decrease their fossil fuels consumption, and the fact that the buildings sector became the major end-use energy consumer. Moreover, there are no national studies regarding the best technical and financial strategies, that need to be adopted in order to increase the energy efficiency of residential multi-unit housing.

In this study, a block of flats composed of 32 apartments ( $1300 \mathrm{~m}^{2}$ total surface) was subject to a retrofit strategy, involving, among others solutions, changing the illumination system and integrating renewable energy sources to decrease the energy requirements for electrical devices and hot water preparation. The project's objective was to decrease the overall energy consumption with 30\%, considered to provide the best technical and economical solution. The total investment was $194.762 €$. While it was considered that only $30 \%$ are paid immediately by the owners, the rest of the sum was paid through debt over 15 years. The resulted overall savings are quantified by approx. $151.000 \mathrm{kWh}$ energy, 99 $\mathrm{tCO}_{2}$ emissions and $47.451 €$ annual savings and revenue. Moreover, the 7.3 year-equity payback time increases the project's feasibility.

Future researches are ongoing, and this study will extend to analyse more efficiency strategies and more type of buildings, including residential - attached and detached dwellings, commercial and institutional. Moreover, this paper represents the starting point of more complex research strategies, involving the integration of multi-objective optimization methods, used to find the optimal solution for any buildings. This complex mathematical approach will be integrated within a user-friendly interface and is intended for non-expert. The idea was proposed for financing through national postdoctoral research projects competition.

\section{References}

Anastastiu, B. (2011, November). Principles for Nearly Zero-Energy Buildings. Retrieved January 13, 2017, from http://bpie.eu/

Consultation on Directive 2010/31/EU on the Energy Performance of Buildings (Recast). (2011). 
Anastastiu, B. (Ed.). (2011, August). EUROPE'S BUILDINGS UNDER THE MICROSCOPE A country-by-country review of the energy performance of buildings. Retrieved December 13, 2017, from http://bpie.eu/.

Anastastiu, B. (2012, August). Implementing nearly Zero-Energy Buildings (nZEB) in Romania - towards a definition and roadmap. Retrieved January 10, 2017, from http://bpie.eu/wp-content/uploads/2015/10/nZEB-Full-Report-Romania.pdf.

PICBE | 155

Energy efficiency and energy consumption in the household sector. (2015, September 04). Retrieved February 14, 2017, from https://www.eea.europa.eu/data-and-maps/indicators/energy-efficiency-andenergy-consumption-5.

România, Romanian Ministry of Energy. (2017). Romanian Energy Strategy for 2016-2020. Bucharest.

Transposition of Article 14(5)-(8) of the Energy Efficiency Directive (2012/27/EU) in Scotland: a consultation. (2014). Edinburgh: Scottish Government.

Ionescu, C., Baracu, T., Vlad, G., Necula, H., \& Badea, A. (2015). The historical evolution of the energy efficient buildings. Renewable and Sustainable Energy Reviews,49, 243-253. doi:10.1016/j.rser.2015.04.062.

Carutasiu, M., Ionescu, C., Necula, H., \& Badea, A. (2015). The efficient management of thermal energy gained in a low energy building. Quality - Access to Success,16(148), 91-95.

Danu, A., Tanasiev, V., Carutasiu, M., \& Badea, A. (2016). Achieving high energy performances for low energy buildings in Romanian climate using green energy. U.P.B. Scientific Bulletin,78(4), 239-248.

Carutasiu, M., Tanasiev, V., Ionescu, C., Danu, A., Necula, H., \& Badea, A. (2015). Reducing energy consumption in low energy buildings through implementation of a policy system used in automated heating systems. Energy and Buildings,94, 227-239. doi:10.1016/j.enbuild.2015.03.008.

Anastastiu, B. (Ed.). (2014). Renovating Romania - A strategy for the energy renovation of Romania's building stock. Retrieved January 10, 2017, from http://bpie.eu/

Connolly, D., Lund, H., Mathiesen, B., \& Leahy, M. (2010). A review of computer tools for analysing the integration of renewable energy into various energy systems. Applied Energy,87(4), 1059-1082. doi:10.1016/j.apenergy.2009.09.026

Leng, G., Monarque, A., Graham, S., Higgins, S., \& Cleghorn, H. (2014, June). RETSCreen International: Results and Impacts 1996 - 2012 (Tech. No. 1). Retrieved January 10, 2017, from Minister of Natural Resources Canada website: http://igs.nigc.ir/STANDS/ARTIC/GN-02.PDF

Minister of Natural Resources Canada. (2005, September). Clean Energy Project Analysis Third Edition RETScreen ${ }^{\circledR}$ Engineering \& Cases Textbook. Retrieved January 13, 2017, from http://publications.gc.ca/collections/collection_2007/nrcanrncan/M154-13-2005E.pdf

Lee, K., Lee, D., Baek, N., Kwon, H., \& Lee, C. (2012). Preliminary determination of optimal size for renewable energy resources in buildings using RETScreen. Energy,47(1), 83-96. doi:10.1016/j.energy.2012.08.040 
Salata, F., Vollaro, A. D., \& Vollaro, R. D. (2014). A Case Study of Technical and Economic Comparison among Energy Production Systems in a Complex of Historic Buildings in Rome. Energy Procedia,45, 482-491. doi:10.1016/j.egypro.2014.01.052

Kim, J., Hong, T., Jeong, J., Lee, M., Koo, C., Lee, M., Ji, C., Jeong, J. (2016). An integrated multiobjective optimization model for determining the optimal solution in the solar thermal energy system. Energy,102, 416-426. doi:10.1016/j.energy.2016.02.104

PICBE $\mid 156$

Koo, C., Hong, T., Lee, M., \& Kim, J. (2016). An integrated multi-objective optimization model for determining the optimal solution in implementing the rooftop photovoltaic system. Renewable and Sustainable Energy Reviews, 57, 822-837. doi:10.1016/j.rser.2015.12.205. 